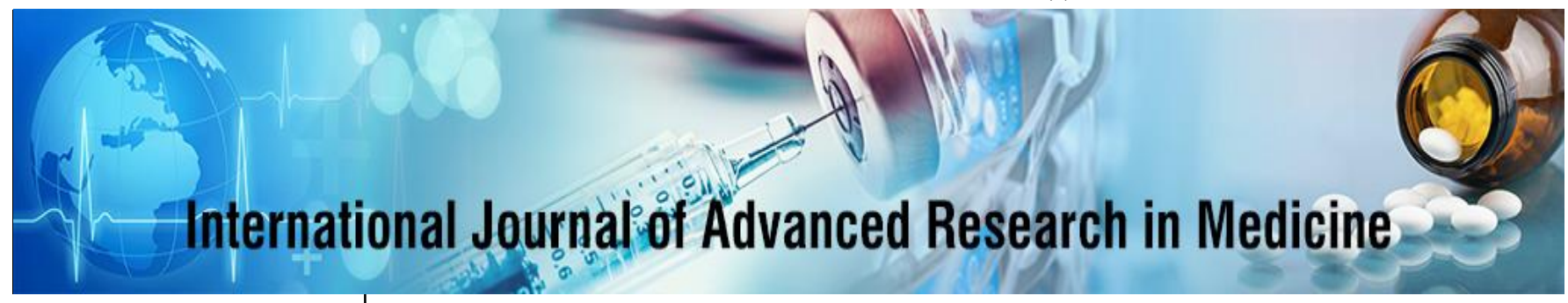

E-ISSN: 2706-9575

P-ISSN: 2706-9567

IJARM 2021; 3(2): 367-371

Received: 17-03-2021

Accepted: 20-06-2021

Dr. Ashish Joshee

Assistant Professor,

Department of Pathology, Dr.

S.N. Medical College, Jodhpur,

Rajasthan, India

Dr. Rajni Joshee

Senior Professor, Department of Pathology, Dr. S.N. Medical College, Jodhpur, Rajasthan, India
Corresponding Author:

Dr. Ashish Joshee

Assistant Professor,

Department of Pathology, Dr.

S.N. Medical College, Jodhpur,

Rajasthan, India

\section{Breast FNA cytology reporting using new proposed IAC Yokohama reporting system: A single institution retrospective study}

\author{
Dr. Ashish Joshee and Dr. Rajni Joshee
}

DOI: $\underline{\text { https://doi.org/10.22271/27069567.2021.v3.i2f.273 }}$

\begin{abstract}
Introduction: Breast lumps are a common presenting complaint in general practice. Breast cancers are the most common cancers diagnosed over the world along with unfortunate rise in number of mortality due to them. Proper diagnostic evaluation is necessary. The fine needle aspiration cytology (FNAC) examination of breast lumps is important as it can be used either to differentiate between benign and malignant breast lesion or as an adjunct to core needle biopsy. In 2016 the IAC Yokohama five category reporting system was proposed to allow uniform reporting of breast FNA aspirates.

Aim: The current study aims to reclassify breast lump aspirates using the proposed Yokohama reporting system and also to assess the risk of malignancy of each category.

Materials and Methods: This single institution retrospective study included female breast lump FNAC cases over 4 year period. Clinical details of included cases were recorded from archives. Cytology slides were reevaluated as per new reporting system and the histopathology correlation was done where available. Statistical analysis was performed. Risk of malignancy of each category was calculated.

Results: 649 breast FNAC cases were studied of average age 36.97 years. Maximum cases were in benign category followed by malignant category. Fibroadenoma was most common benign diagnosis. The risk of malignancy was $3.17 \%$ in benign category and $95.45 \%$ in suspicious for malignancy category. The diagnostic accuracy in current study was $97.83 \%$.

Conclusion: Use of a standard categorical cytology reporting system will give improved reports for better patient care.
\end{abstract}

Keywords: Yokohama, FNAC, risk of malignancy, category, atypical

\section{Introduction}

Palpable breast lesions are a common presenting complaint in females in hospitals. Their proper evaluation with prompt diagnosis is necessary for complete treatment of the condition with increasing numbers of breast malignancy cases rising all over the world. Breast cancers in females are now the most common cancers diagnosed worldwide ${ }^{[1]}$ and their number has been increasing in Indian women over last few decades. Also there has been a constant unfortunate rise in mortality rates due to breast cancers. Fine needle aspiration cytology (FNAC) as a diagnostic method in palpable lesions is widely used as it is considered rapid, minimally invasive procedure with faster results and it can be used either as a screening method to differentiate between benign and malignant breast lesion or as an adjunct to the gold standard method of core needle biopsy ${ }^{[2]}$. In the Indian context FNAC becomes more significant as many areas may lack setup for core biopsy.

In 2016 IAC formed a "Breast Group" that included specialists of different fields who met at the International Congress of cytology held at Yokohama with the aim of forming a standardized reporting system of breast cytology that would give uniform terms, allow consistent reporting and provide best practice guidelines that eventually would help helping the treating clinician in proper management of the lesion ${ }^{[3]}$.

The IAC Yokohama system for reporting breast cytology has proposed five distinct categories of reporting- 1-Insufficient material category 2- Benign category 3- Atypical, probably benign category 4- Suspicious for malignancy, probably in situ or invasive carcinoma category 5- Malignant category ${ }^{[3]}$. The present study aims to classify female breast FNAC samples as per the new reporting system and to calculate risk of malignancy 
(ROM) for each category and finally correlate with histopathology report where possible to calculate diagnostic accuracy.

\section{Materials and Methods}

In the present retrospective study the female breast FNAC specimens received in our department from January 2017 to December 2020 were studied. During this duration total 649 female breast FNAC were conducted after informed consent. The relevant clinical details were retrieved from the departmental records and LIS. All case smears which were Giemsa stained were retrieved from department archives. Reclassification of these cases was done as per IAC Yokohama reporting system.

Histopathology was considered standard of diagnosis in the study. All cases which were malignant both on cytology and histopathology were considered true positive (TP) while true negative (TN) were cases diagnosed benign on both cytology and histopathology. False positive (FP) were cases given malignant on cytopathology but were found benign on histopathology. Those cases which were given as benign lesion on cytology but were found malignant on histopathology were considered false negative cases (FN). The cytology and histopathology diagnosis were compared where possible and analysis was done to calculate values of ROM, sensitivity, specificity, positive predictive value (PPV), negative predictive value (NPV) and diagnostic accuracy.

\section{Results}

The current retrospective study included 649 breast FNAC cases conducted over 4 year period. Histopathology samples were available of 363 cases and these were considered for correlation. We had a wide age group range of the cases ranging from 15 years to 90 years with average age being 36.97 years. Maximum cases were from the age group of 21 to 30 years.

The cytology slides were reexamined and were classified as per Yokohama reporting system and tabulation of results was done. Maximum cases were categorized into category 2 Benign (419 cases) and the category 5 (malignant) had second most number of cases (168). The most common cytological diagnosis in the study and the most common benign diagnosis in the study was fibroadenoma (Figure 1) with 242 cases which was $57.75 \%$ of all benign diagnoses. The most common malignant cytology diagnosis was invasive carcinoma NST (Figure 2) with 125 cases out of 168 malignant category cases. The youngest age at which malignancy was diagnosed by cytology was 18 years while the oldest case was 90 years old.

Histopathology correlation was available for 221 cases out of 419 cases categorized as benign on cytology out of which 7 cases were found malignant on histopathology. In the cytological malignant category cases, histopathology was available for 102 cases and all were in concordance with cytological diagnosis. Histopathology correlation was available for 6 cases diagnosed insufficient on cytology and out of these 1 case was found malignant on histopathological examination. This could be due to aspiration not being done on representative area. 4 out of 12 cases of atypical probably benign category and 21 out of 22 suspicious category cases turned out malignant on histopathology. This could be attributed to more amount of tissue being available for examination in histopathology.
The most common benign histopathological diagnosis was fibroadenoma while invasive carcinoma NST was the most common malignant diagnosis. The ROM calculation of each category is shown in table 1 .

Table 1: ROM calculation of each Yokohama system category

\begin{tabular}{|c|c|c|c|c|c|}
\hline Category & Cytology & Histopathology & Benign & Malignant & $\begin{array}{c}\text { ROM } \\
(\%)\end{array}$ \\
\hline Insufficient & 18 & 6 & 5 & 1 & 16.6 \\
\hline Benign & 419 & 221 & 214 & 7 & 3.17 \\
\hline $\begin{array}{c}\text { Atypical, } \\
\text { likely benign }\end{array}$ & 18 & 12 & 8 & 4 & 33.3 \\
\hline $\begin{array}{c}\text { Suspicious of } \\
\text { malignancy }\end{array}$ & 26 & 22 & 1 & 21 & 95.45 \\
\hline Malignant & 168 & 102 & 0 & 102 & 100 \\
\hline
\end{tabular}

The various histopathological diagnoses found in the current study are shown in table 2 .

Table 2: Various histopathological diagnoses in the study

\begin{tabular}{|c|c|c|c|}
\hline Benign diagnosis & $\begin{array}{c}\text { Number } \\
\text { of cases }\end{array}$ & Malignant diagnosis & $\begin{array}{c}\text { Number of } \\
\text { cases }\end{array}$ \\
\hline Fibroadenoma & 124 & $\begin{array}{c}\text { Invasive ductal } \\
\text { carcinoma }\end{array}$ & 108 \\
\hline Fibrocystic disease & 8 & Lobular carcinoma & 3 \\
\hline Duct ectasia & 11 & $\begin{array}{c}\text { Squamous cell } \\
\text { carcinoma }\end{array}$ & 1 \\
\hline Hyperplasia & 18 & $\begin{array}{c}\text { Carcinoma with } \\
\text { medullary features }\end{array}$ & 8 \\
\hline Benign Phyllodes & 7 & Malignant Phyllodes & 3 \\
\hline Inflammatory lesion & 65 & DCIS & 6 \\
\hline & & Metaplastic carcinoma & 1 \\
\hline & & Metastatic lesion & 5 \\
\hline
\end{tabular}

The histopathology diagnosis has been considered as gold standard and statistical calculations were done accordingly. The statistical analysis and calculation are shown in table 3.

Table 3: Statistical analysis in current study

\begin{tabular}{|c|c|}
\hline True Positive (TP) & 102 \\
\hline False Positive (FP) & Nil \\
\hline True Negative (TN) & 214 \\
\hline False Negative (FN) & 7 \\
\hline Sensitivity & $93.58 \%$ \\
\hline Specificity & $100 \%$ \\
\hline Positive predictive value (PPV) & $100 \%$ \\
\hline Negative predictive value (NPV) & $96.83 \%$ \\
\hline Diagnostic accuracy & $97.83 \%$ \\
\hline
\end{tabular}

Sensitivity, specificity, positive predictive value and negative predictive value in the current study was calculated and were $93.58 \%, 100 \%, 100 \%$ and $96.83 \%$ respectively. The diagnostic accuracy of IAC Yokohama breast cytology reporting system in this study was calculated as $97.83 \%$.

\section{Discussion}

Breast lesions are a common site sampled using FNAC especially in developing countries. FNAC has been recognized as an easy, relatively less painful and rapid diagnostic method that can be a useful adjunct to the gold standard diagnosis of biopsy of lesion. ${ }^{[2]}$ The IAC proposed the new comprehensive Yokohama breast cytology reporting system to give a categorization and uniform reporting terminology for pathologists worldwide which would help standardize breast cytology reporting. Each of 
the 5 categories has been given a distinct definition and description. The system also gives best practice guides for suggested management of each category and their ROM. The final aim of the system is to allow continuous improvement in breast cytology interpretation and thus helping the clinician managing the breast lesion ${ }^{[3]}$.

The present study included FNAC samples of 649 female breast lesions making this a smaller study than those done by Montezuma D et al. ${ }^{[4]}$ Wong S et al. ${ }^{[5]}$ Wai CJ et al. ${ }^{[6]}$ Nargund A et al. ${ }^{[7]}$ Appuroopa $\mathrm{M}$ et al. ${ }^{[8]}$ but more cases than Kamatar PV et al. ${ }^{[9]}$ and Tejeswini V et al. ${ }^{[10]}$ The study by Montezuma D et al. ${ }^{[4]}$ was the first to categorize breast lesions by the new system and currently one of the largest studies done on the topic. In the present study histopathology diagnosis was available in 363 cases and these were used for statistical analysis.

Category 1 Insufficient are those cytology smears that are either too sparsely cellular or too poorly smeared or fixed to allow a cytomorphological diagnosis. Out of 18 cases of this category 6 cases had histopathology correlation and one case was diagnosed as malignant. The ROM for this category was $16.6 \%$. This was higher than the studies by Kamatar PV et al. (0\%) ${ }^{[9]}$, Appuroopa M et al. (5\%) ${ }^{[8]}$, Nargund A et al. (7.69\%) ${ }^{[7]}$, Wong S et al $(2.6 \%)^{[5]}$ and Montezuma D et al. $(4.8 \%)^{[4]}$. The study by Tejeswini V et al. ${ }^{[10]}$ had a higher ROM of $22.22 \%$ and Hoda RS et al. ${ }^{[1]}$ at $30.3 \%$ for this category. So a proper aspiration technique, rapid on-site evaluation (ROSE) of smears and availability of radiological investigations will allow better interpretation in such cases.

Category 2 Benign cytology smears are those having well defined benign cytological features, which may or may not be diagnostic of a specific benign lesion. Inflammatory lesions, cysts, benign neoplasms and epithelial hyperplasia are part of this category. Maximum cases were in this category on cytology and of the 221 cases with histopathology correlation, 214 were consistent with benign diagnoses. In the remaining 7 cases 5 were diagnosed as invasive carcinoma and 2 of DCIS. The ROM of this category was $3.17 \%$ which was less than study of Tejeswini V et al. $(5.32 \%)^{[10]}$ Nargund A et al. $(15.26 \%)^{[7]}$, Kamatar PV et al. (4\%) ${ }^{[9]}$, Hoda RS et al. $(4.7 \%)^{[11]}$ but higher than studies of Appuroopa M et al. (1.2\%) ${ }^{[8]}$ Montezuma D et al. $(1.4 \%)^{[4]}$ Wong S et al. $(1.7 \%)^{[5]}$.

Category 3-Atypical breast cytology is defined as presence of cytological features seen predominantly in benign processes or lesion but with presence of some uncommon features that may be seen in malignant lesion. The figure 3 shows a aspirate from a breast lump that was categorized as atypical cytology. The ROM of this category was $33.3 \%$ because 4 cases where histopathological correlation was were diagnosed as malignant. 2 were diagnosed as borderline Phyllodes tumor and 1 each as DCIS and invasive carcinoma. The ROM in the current study was higher than studies of Montezuma D et al. (13-15.7\%) ${ }^{[4]}$,
Wai CJ et al. (13\%) ${ }^{[6]}$, Wong S et al. $(15.7 \%)^{[5]}$, Tejeswini $\mathrm{V}$ et al. (26.31\%) ${ }^{[10]}$, Appuroopa $\mathrm{M}$ et al. $(12.5 \%)^{[8]}$ but lower than Kamatar PV et al. $(66 \%)^{[9]}$ and Nargund A et al. $(65.38 \%)^{[7]}$. The management of this category includes correlation with clinical and imaging findings along with repeat of FNAC. ${ }^{[2]}$ Provision of proceeding to core needle biopsy is given if other findings are highly atypical too.

Category 4 Suspicious of malignancy terminology is used when there are some cytological features present which are usually found in malignant lesions but with insufficient malignant features either in number or quality to make a definite diagnosis of malignancy. Histopathology of 22 cases out of 26 in this category was available and only one case was diagnosed as a benign lesion (hyperplasia). The ROM here was $95.45 \%$. This was higher than the studies of Wong S et al. (84.6\%) [5], Kamatar PV et al. (83\%) [9], Nargund A et al. (83.3\%) ${ }^{[7]}$, Appuroopa M et al. $(93.65 \%)$ ${ }^{[8]}$ but slightly lower than studies of Wai CJ et al. $(97.1 \%)^{[6]}$ and Tejeswini V et al. $(100 \%)^{[10]}$.

Category 5 Malignant cytological diagnosis is given when there are definite cytological features. All 102 cases of this category whose histopathology was available were diagnosed as malignant. The ROM of $100 \%$ was similar to Montezuma D et al. (100\%) ${ }^{[4]}$, Wai CJ et al. (100\%) ${ }^{[6]}$, Wong S et al. (99.5\%) [5], Nargund A et al. (99.18\%) [7], Appuroopa M et al. $(100 \%)^{[8]}$, Tejeswini V et al. $(100 \%)^{[10]}$. The study by Wong $\mathrm{S}$ et al. had higher number of cases and also incorporated the rapid on-site evaluation (ROSE) technique thus decreasing ROM in categories 1,2 and 3 as compared to our results ${ }^{[5]}$.

Wai CJ et al. conducted his study evaluating breast masses using techniques of ultrasound and core needle biopsy along with FNAC (Triple test) leading to a different value of ROM in categories 3 and 4 than those of our study as these tests provide additional help in ruling out or confirming suspicious malignant lesion ${ }^{[6]}$.

Apuroopa et al. considered radiological findings in their study which helped to rule out false positive malignant cases especially in category 3 and 4 leading to lower ROM ${ }^{[8]}$.

The ROM of categories 1,2 and 3 was higher than that given by Field AS et al. in the article defining the Yokohama breast reporting system ${ }^{[3]}$. This could be because the current study was done at a tertiary care center without proper cancer referral system.

Sensitivity, specificity, positive predictive value and negative predictive value in the current study was calculated and were $93.58 \%, 100 \%, 100 \%$ and $96.83 \%$ respectively. These were similar to the values obtained by Montezuma D et al. ${ }^{[4]}$ and Kamatar PV et al. ${ }^{[9]}$ Diagnostic accuracy of FNAC in our study was $97.83 \%$ which was similar to result of Kamatar PV et al. ${ }^{[9]}$ and Cunha MD et al. ${ }^{[12]}$ The study by McHugh KE et al. ${ }^{[13]}$ done on 695 breast FNAC cases had a diagnostic accuracy of $89 \%$. De Rosa F et al. ${ }^{[14]}$ studied 4624 ultrasound guided FNAC cases and their study had a diagnostic accuracy of $92.82 \%$. Statistical values of various studies are compared with current study in table 4.

Table 4: Comparing statistical values of various similar studies

\begin{tabular}{|c|c|c|c|c|c|c|}
\hline & Current study & $\begin{array}{c}\text { Montezuma D } \\
\text { et al. }{ }^{[4]}\end{array}$ & $\begin{array}{c}\text { Kamatar PV } \\
\text { et al. }{ }^{[9]} \\
\end{array}$ & $\begin{array}{c}\text { Appuroopa M } \\
\text { et al. }{ }^{[8]} \\
\end{array}$ & $\begin{array}{c}\text { Cunha MD } \\
\text { et al. } .^{[12]}\end{array}$ & $\underset{[13]}{\operatorname{McHugh~KE} \text { et al. }}$ \\
\hline Sensitivity & 93.58 & \begin{tabular}{|l|}
97.56 \\
\end{tabular} & \begin{tabular}{|l|}
94.59 \\
\end{tabular} & 95.9 & 94.4 & 85 \\
\hline Specificity & 100 & 100 & 98.9 & 97.89 & 100 & 75 \\
\hline Positive predictive value & 100 & 100 & 98.59 & 96.79 & 100 & 69 \\
\hline Negative predictive value & 96.83 & 98.62 & 95.74 & 97.64 & 91.66 & 88 \\
\hline Diagnostic accuracy & 97.83 & 99.11 & 96.97 & 98.57 & 96.55 & 89 \\
\hline
\end{tabular}


The meta-analysis study by Hoda RS et al. ${ }^{[11]}$ demonstrates that the diagnostic categories of the new IAC Yokohama System each carry an implied ROM, which increases from the benign to malignant categories. This was also noted in our study.

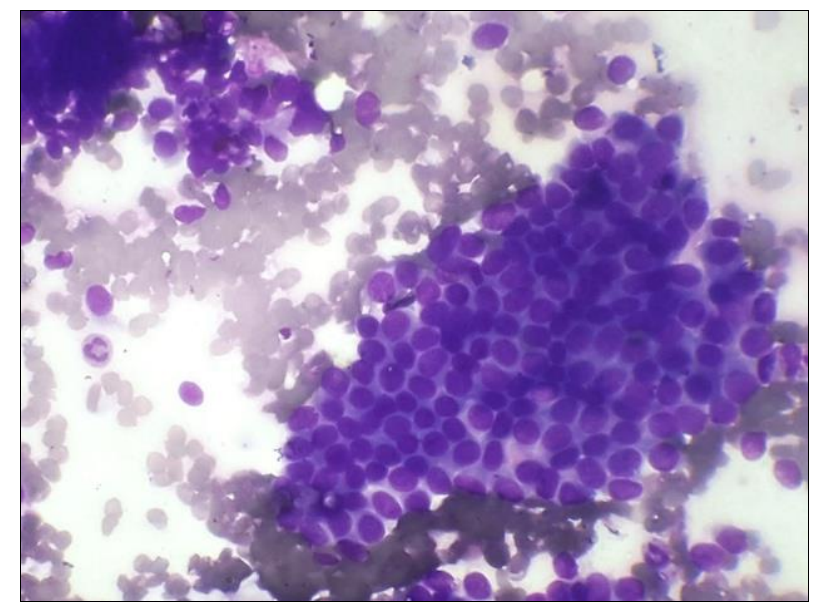

Fig 1: Fibroadenoma cytology smear showing cohesive clusters of benign ductal cells and few bare nuclei in background. 40x, Giemsa stain

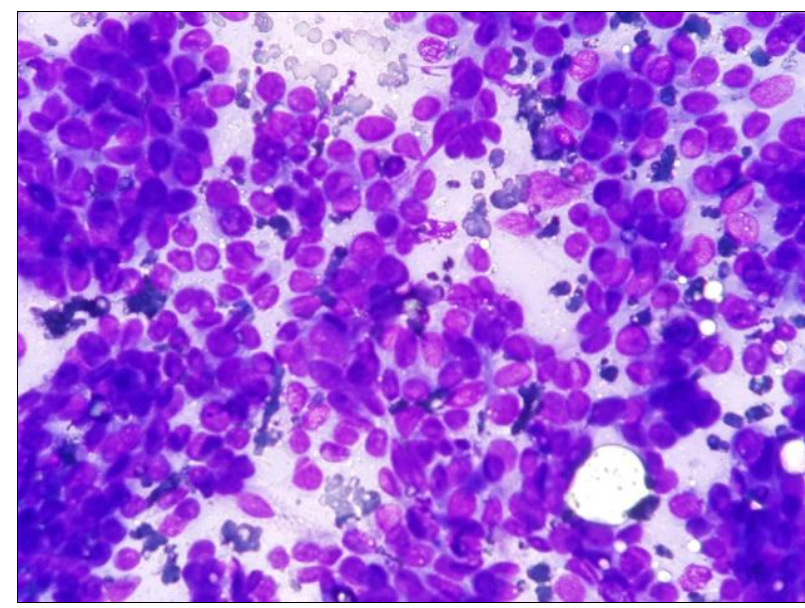

Fig 2: Malignant category aspirate showing irregular clusters of atypical cells that have enlarged hyperchromatic pleomorphic nuclei. Carcinoma breast NST. 40x, Giemsa stain

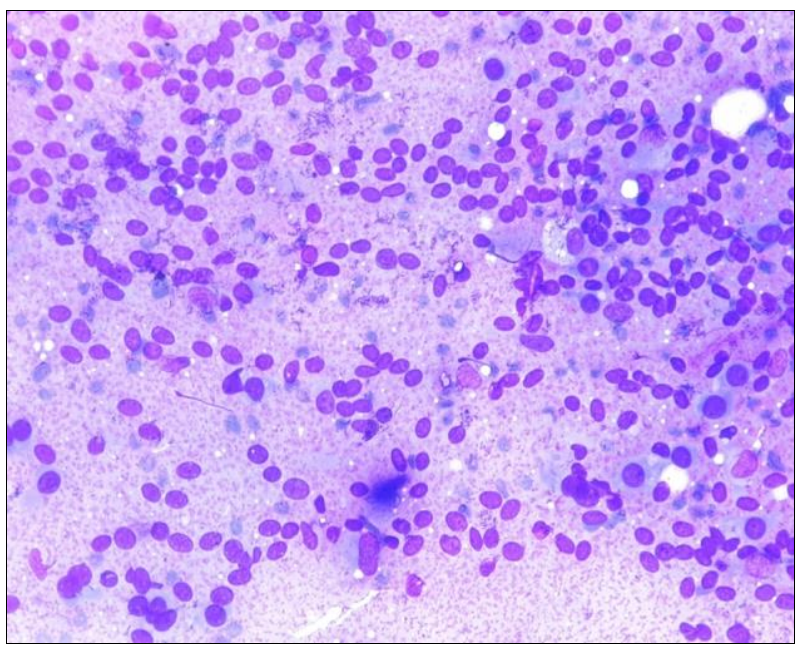

Fig 3: 'Atypical likely benign' category smear showing dispersed cells having oval to plump nuclei and slight pleomorphism. This case was diagnosed as benign Phyllodes tumor on histopathology. Giemsa stain

\section{Conclusion}

FNAC of female breast lesions is a rapid, effective diagnostic technique. The recent simple standardized IAC Yokohama breast cytology reporting system provides uniform reporting terminology in five distinctly defined diagnostic categories. It provides best practice guidelines and helps in predicting ROM. Overall its aim is to improve breast cytology interpretation and to clearly convey the cytological diagnosis from the pathologist to treating physician thus leading to better patient care.

\section{References}

1. Sung $\mathrm{H}$, Ferlay J, Siegel RL, Laversanne $\mathrm{M}$, Soerjomataram I, Jemal A et al. Global cancer statistics 2020: GLOBOCAN estimates of incidence and mortality worldwide for 36 cancers in 185 countries. CA Cancer J Clin 2021:71:209249. https://doi.org/10.3322/caac. 21660

2. Pandya AN, Shah NP. Breast fine needle aspiration cytology reporting: A study of application of probabilistic approach. Indian Medical Gazette. 2013, 54-9.

3. Field AS, Raymond WA, Rickard M, Arnold L, Brachtel EF, Chaiwun B et al. The international academy of cytology Yokohama system for reporting breast fine-needle aspiration biopsy cytopathology. Acta cytological 2019;63(4):257-73.

4. Montezuma D, Malheiros D, Schmitt FC. Breast fine needle aspiration biopsy cytology using the newly proposed IAC Yokohama System for reporting breast cytopathology: the experience of a single institution. Acta cytological 2019;63(4):274-9.

5. Wong S, Rickard M, Earls P, Arnold L, Bako B, Field AS. The international academy of cytology Yokohama system for reporting breast fine needle aspiration biopsy cytopathology: A single institutional retrospective study of the application of the system categories and the impact of rapid onsite evaluation. Acta cytological 2019;63(4):280-91.

6. Wai CJ, Al-Mubarak G, Homer MJ, Goldkamp A, Samenfeld-Specht M, Lee Y et al. A modified triple test for palpable breast masses: the value of ultrasound and core needle biopsy. Annals of surgical oncology 2013;20(3):850-5.

7. Nargund A, Mohan RH, Pai MM, Sadasivan B, Dharmalingam P, Chennagiri P. Demystifying Breast FNAC's Based on the International Academy of Cytology, Yokohama Breast Cytopathology System-A Retrospective Study. Journal of Clinical \& Diagnostic Research 2021, 15(3).

8. Apuroopa M, Chakravarthy V, Rao D. Application of Yokohama system for reporting breast Fine Needle Aspiration Cytology in correlation with histopathological and radiological findings. Annals of Pathology and Laboratory Medicine 2020;7(4):A210215.

9. Kamatar PV, Athanikar VS, Dinesh US. Breast Fine Needle Aspiration Biopsy Cytology Reporting using International Academy of Cytology Yokohama System-Two year retrospective study in Tertiary Care Centre in Southern India. National journal of laboratory medicine 2019, 8(3).

10. Tejeswini V, Chaitra B, Renuka IV, Laxmi K, Ramya $\mathrm{P}$, Sowjanya KK. Effectuation of international academy 
of cytology Yokahama reporting system of breast cytology to assess malignancy risk and accuracy. Journal of Cytology 2021;38(2):69.

11. Hoda RS, Brachtel EF. International Academy of Cytology Yokohama System for reporting breast fineneedle aspiration biopsy cytopathology: a review of predictive values and risks of malignancy. Acta cytological 2019;63(4):292-301.

12. Cunha MD, Kini RG. Breast fine needle aspiration biopsy cytology reporting using international academy of cytology Yokohama system: A single institution experience.

13. McHugh KE, Bird P, Sturgis CD. Concordance of breast fine needle aspiration cytology interpretation with subsequent surgical pathology: An 18-year review from a single Sub-Saharan African institution. Cytopathology 2019;30(5):519-25.

14. De Rosa F, Migliatico I, Vigliar E, Salatiello M, Pisapia $\mathrm{P}$, Iaccarino A et al. The continuing role of breast fine-needle aspiration biopsy after the introduction of the IAC Yokohama system for reporting breast fine needle aspiration biopsy cytopathology. Diagnostic Cytopathology 2020;48(12):1244-53. 